\title{
Milligram per Hour
}

National Cancer Institute

\section{Source}

National Cancer Institute. Milligram per Hour. NCI Thesaurus. Code C66969.

A unit of mass flow rate equivalent to the rate at which one thousandth of a gram of

matter crosses a given surface or is delivered to a given object or space over a period of time equal to one hour. 